\title{
Use of Modified Colloids and Membranes to Remove Metal Ions from Contaminated Solutions
}

\author{
Mohd Akmali Mokhter ${ }^{1}$, Claire Magnenet ${ }^{1}$, Sophie Lakard ${ }^{1}$, Myriam Euvrard ${ }^{1}$, \\ Moumin Aden ${ }^{1}$, Sébastien Clément ${ }^{2}$ (D), Ahmad Mehdi ${ }^{2}$ and Boris Lakard ${ }^{1, *}$ \\ 1 Institut UTINAM UMR CNRS 6213-Université Bourgogne Franche-Comté, 16 Route de Gray, \\ 25030 Besançon CEDEX, France; akmali90@gmail.com (M.A.M.); claire.magnenet@univ-fcomte.fr (C.M.); \\ sophie.lakard@univ-fcomte.fr (S.L.); myriam.euvrard@univ-fcomte.fr (M.E.); \\ moumin.aden@utinam.cnrs.fr (M.A.) \\ 2 Institut Charles Gerhardt UMR CNRS 5253-Université de Montpellier, Place Eugène Bataillon, \\ 34095 Montpellier CEDEX, France; sebastien.clement02@univ-montp2.fr (S.C.); \\ ahmad.mehdi@umontpellier.fr (A.M.) \\ * Correspondence: boris.lakard@univ-fcomte.fr; Tel.: +33-81-66-20-46
}

Received: 12 March 2018; Accepted: 4 May 2018; Published: 6 May 2018

\begin{abstract}
An efficient process was developed allowing the removal of metal ions from polycontaminated aqueous solutions by combining modified colloids and membranes. Firstly, filtration experiments were performed using polyethersulfone membranes modified by a self-assembled multilayer film of polyelectrolytes. These polymer-modified membranes allowed the uptake of more than $90 \%$ of the metal ions initially present in the contaminated solutions (for solutions concentrated at $50 \mathrm{mg} \mathrm{L}^{-1}$ ). Secondly, adsorption experiments were carried out with colloidal silica encapsulated with carboxymethyl chitosan $\left(\mathrm{SiO}_{2}-\mathrm{CMCS}\right)$ or with mesoporous silica functionalized by grafting of 1,4,8,11-tetraazacyclotetradecane, i.e., cyclam $\left(\mathrm{SiO}_{2}\right.$-cyclam). The adsorption capacity of these compounds was shown to be higher than numerous other literature-known adsorbents, reaching 68 and $61 \mathrm{mg} \mathrm{g}^{-1}$ towards $\mathrm{Cu}$ (II) for $\mathrm{SiO}_{2}-\mathrm{CMCS}$ and $\mathrm{SiO}_{2}$-cyclam, respectively. Finally, by coupling adsorption with ultrafiltration in the tangential mode, the removal of $\mathrm{Cu}(\mathrm{II}), \mathrm{Ni}$ (II) and $\mathrm{Zn}$ (II) ions was found to be improved, allowing to reach a removal efficiency of $99 \%$ towards $\mathrm{Cu}$ (II), $\mathrm{Ni}(\mathrm{II})$ and $\mathrm{Zn}$ (II) ions at a metal concentration of $50 \mathrm{mg} \mathrm{L}^{-1}$, and a promising removal efficiency around $70 \%$ at a very high metal concentration of $1200 \mathrm{mg} \mathrm{L}^{-1}$. The mechanisms involved in the capture of the metal ions by modified membranes and colloids are also discussed.
\end{abstract}

Keywords: hybrid silica; adsorbents; interfaces; metal removal; chemical functionalization; membrane filtration; water treatment

\section{Introduction}

Clean water is an essential element for all living organisms to sustain life. However, with the rapid population growth and the accelerated process of modernization, the demand for clean water is increasing continuously [1]. In particular, the demand for clean water has greatly increased in agricultural, industrial and domestic sectors consuming nearly all available fresh water. In addition, water resources are the final recipients of terrestrial pollutants and effluent discharges from industrial and domestic sources, which generate toxic effects on living organisms and ecosystems [2]. Especially, metallurgical industry and chemical manufacturing have generated large amounts of wastewater containing aquatic contaminants such as heavy metal ions or dyes $[3,4]$. The presence of heavy metal ions in water, even in trace quantities, brings many severe challenges to the public health and environmental ecosystems due to the toxicity and non-biodegradability of heavy metal 
ions $[5,6]$. Consequently, removing metal pollutants from wastewater has become a crucial topic of worldwide concern.

That is why tremendous efforts have been done during the past few decades to develop numerous techniques for treating the contaminated wastewaters. Among them, most frequently used techniques consist in chemical treatments (such as chemical precipitation, ion-exchange, coagulation, and flotation), electrochemical treatments (electrolysis and electrodialysis), physical treatments (adsorption and membrane filtration), or biological treatments, as extensively reviewed by Fu et al. [7].

In particular, membrane nanofiltration and reverse osmosis are two techniques which have already been used successfully to remove metal ions with a high removal efficiency. For example, the retention of $\mathrm{Cu}^{2+}$ and $\mathrm{Ni}^{2+}$ ions increased up to $99.5 \%$ by using $\mathrm{Na}_{2}$ EDTA with the osmosis process [8]. However, this technique suffers from a major drawback, which is its high power consumption due to the pumping pressures, and the restoration of the membranes. Concerning nanofiltration, this technique has attractive advantages such as high separation efficiency, easy operation, and easy to scale up $[9,10]$. However, nanofiltration suffers from its high energy consumption and cost due to the need to perform the filtration of metal ions at high operating pressure (10-30 bars) [11,12].

An alternative to these techniques is ultrafiltration which is a more economic membrane technique working at low pressure. In most cases, the metal removal efficiency obtained with ultrafiltration membranes is slightly lower than the one obtained for nanofiltration membranes, but the cost and energy consumption are also lower when using ultrafiltration technique. In addition, it is possible to improve the performances of ultrafiltration membranes by performing their chemical modification, especially by immersion in polyelectrolyte solutions [13]. Such modification leads to the adsorption of a thin polyelectrolyte film on the surface of the membrane and improves the membrane surface charge density even if the operating pressure remains high [14-16]. To reduce the operating pressure, a solution could be the use of traditional ultrafiltration but it is ineffective at removing dissolved metal ions, in the form of hydrated ions, from aqueous solutions since the pore sizes of the membranes are larger than dissolved ions. To reduce the operating pressure without decreasing the separation performances of the membranes, a more efficient strategy is the use of ultrafiltration membranes chemically modified by self-assembly of polyelectrolyte multilayer films. Such modified membranes have the advantages of promoting both chelation by the chelating functions present in the structure of the polyelectrolyte and electrostatic interactions between metal cations and the charges present in the polyelectrolyte film, without needing a high operating pressure. The efficiency of this strategy has been demonstrated by: (i) our group who modified polyethersulfone membranes by poly(allylamine hydrochloride) and poly(sodium 4-styrene sulfonate) to remove $\mathrm{Cu}(\mathrm{II}), \mathrm{Zn}$ (II) and/or $\mathrm{Ni}(\mathrm{II})$ from aqueous solutions [17-19]; (ii) Qin et al. who modified polyacrylonitrile membranes with polyethyleneimine and poly(sodium 4-styrene sulfonate) to treat $\mathrm{Ni}(\mathrm{II}), \mathrm{Cu}(\mathrm{II}), \mathrm{Zn}$ (II) and $\mathrm{Cd}(\mathrm{II})$ aqueous solutions [20]; and (iii) Kochan et al. who modified polyethersulfone membranes with poly(styrene sulfonate) and polyethylenimine or poly(diallyldimethylammonium chloride) to treat sludge supernatant wastewater [21].

Adsorption is another interesting technique which is simple, effective, flexible, reversible and economic. Activated carbon has probably been the most widely used adsorbent for a long time, but it suffers from a lack of structural and functional tenability and low adsorption capacities [22,23]. Consequently, there is an urgent need for the development of new adsorbents with high adsorption capacity and selectivity to remove heavy metal contaminants from aqueous solutions. Biopolymers containing nitrogen functional groups, such as chitosan, are good candidates for metal adsorption due to their chelation abilities. For example, chitosan has been used as bioadsorbent to perform the removal of metal ions including $\mathrm{Cu}^{2+}, \mathrm{Zn}^{2+}, \mathrm{Ni}^{2+}, \mathrm{Cd}^{2+}$, and $\mathrm{Pb}^{2+}[24,25]$ according to sorption mechanisms described by Guibal et al. [26]. Synthetic materials, such as chemically modified mesoporous silica, can also be prepared to be used as adsorbent. For example, mesoporous silica was used to remove $\mathrm{Ni}^{2+}, \mathrm{Zn}^{2+}, \mathrm{Cd}^{2+}, \mathrm{Co}^{2+}, \mathrm{Cu}^{2+}$ and $\mathrm{Pb}^{2+}$ ions after functionalization by $\mathrm{N}, \mathrm{N}$-dimethyldodecylamine and dodecylamine [27] or by aminopropyl groups [28,29]. Lamellar silica functionalized with amino 
groups were prepared and showed to be highly efficient for metals extraction [30]. Colloidal silica particles can also be used, after functionalization by dimethylsilyl groups [31], chitosan [32], or its derivatives [33], to remove heavy metal ions such as $\mathrm{Cd}^{2+}, \mathrm{Cu}^{2+}$ and $\mathrm{Ni}^{2+}$ ions. Another possibility to remove heavy metal ions consists in using cyclam-modified materials since these tetraaza macrocyclic ligands possess a strong ability to bind transition and heavy metal ions as previously shown by the groups of Salih [34] and Corriu [35].

Another strategy to remove metal ions from wastewater consists in the combination of adsorption and ultrafiltration. The main group developing this strategy is the one from Malamis et al. who had already used combined ultrafiltration-adsorption processes to treat industrial wastewater streams $[36,37]$. In particular, they removed efficiently the metal pollutants contaminating metal plating wastewater [38] and textile wastewater [39].

Considering this literature, cyclam- and chitosan-based materials were chosen in this work for their remarkable binding ability towards heavy metal cations and their possible combination with silica matrix leading hybrid materials by either incorporating cyclam moieties into the mesoporous silica thanks to the sol-gel process, or by encapsulating colloidal silica particles by modified chitosan. Moreover, we proposed to test the feasibility of a strategy combining polyelectrolyte-modified membranes with silica adsorbents modified with cyclam or chitosan derivatives to gain an effective removal of $\mathrm{Cu}(\mathrm{II}), \mathrm{Zn}(\mathrm{II})$ and $\mathrm{Ni}(\mathrm{II})$ ions (Figure 1). Single and poly-contaminated solutions as well as the effect of metal concentration on the filtration and adsorption efficiency were systematically studied. The adsorption capacity of the two adsorbents, which are believed to allow a good chelation of metals, was also compared. The mechanisms allowing the removal of metal ions by the modified membranes and by the adsorbents were finally discussed.

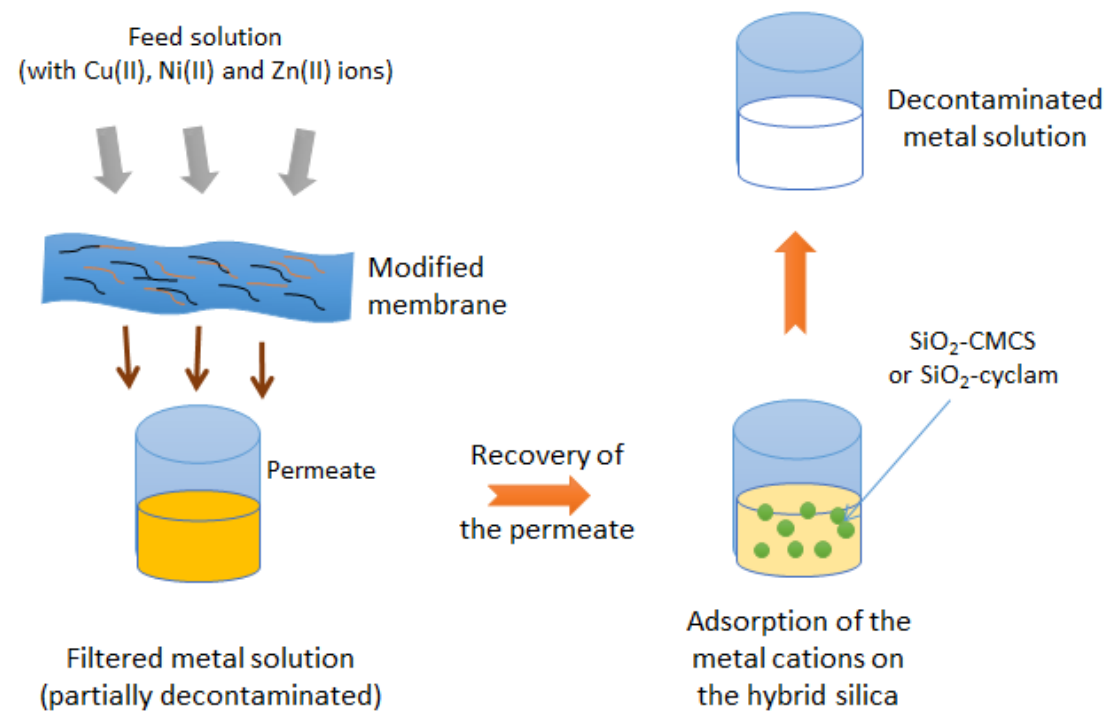

Figure 1. Schematic diagram of the filtration-adsorption treatment process.

\section{Materials and Methods}

\subsection{Reagents}

All the reagents used were of analytical grade and had the highest purity available. Copper (II) chloride (from dihydrate solid, Fisher Chemical (Illkirch, France), 98\% pure), nickel (II) chloride (from hexahydrate solid, Sigma-Aldrich (Saint Quentin Fallavier, France), 98\% pure), and zinc (II) chloride (from solid, Fluka (Saint Quentin Fallavier, France), 98\% pure) solutions were prepared by dissolving required amounts in double deionized water (Milli-Q (Merck Millipore, Molsheim, France), resistivity $18 \mathrm{M} \Omega . \mathrm{cm}$ ). The $\mathrm{pH}$ of the aqueous solutions was adjusted to $\mathrm{pH} 5$ using $\mathrm{HCl}$ or $\mathrm{NaOH}$ at $10^{-1} \mathrm{~mol} \mathrm{~L}^{-1}$ (both from VWR Chemicals (Fontenay sous Bois, France)). Cyclam was purchased from CheMatech (Dijon, France) and used as received. 
The polyelectrolytes used to modify the organic membranes were poly(allylamine hydrochloride) $(\mathrm{PAH}, 58 \mathrm{kDa})$ and sodium poly(styrene sulfonate) (PSS, $70 \mathrm{kDa}$ ). Polyelectrolyte solutions, concentrated at $5 \mathrm{~g} \mathrm{~L}^{-1}$, were prepared in $10^{-2} \mathrm{~mol} \mathrm{~L}^{-1} \mathrm{NaCl}$ (from Sigma-Aldrich) solutions without any $\mathrm{pH}$ adjustment. Tetraethylorthosilicate, 3-chloropropylmethoxysilane and pluronic P123 were purchased from Sigma-Aldrich.

Fumed silica particles (Aerosil 200) were obtained from Evonik Industries (Tokyo, Japan). They have a specific surface area of $200+/-25 \mathrm{~m}^{2} \mathrm{~g}^{-1}$. The molecular weight of chitosan was $150 \mathrm{kDa}$ and its degree of deacetylation was comprised between 68 and $75 \%$. For the synthesis of carboxymethyl chitosan (CMCS), isopropanol, sodium hydroxide, and chloroacetic acid were purchased from Sigma Aldrich.

\subsection{Membranes and Filtration Setup}

The filtration experiments were conducted in a planar membrane module (Pleiade ${ }^{\circledR}$ module from Orelis, Paris, France) with an active area of $0.013 \mathrm{~m}^{2}$. The filtration membranes (Pleiade ${ }^{\circledR}$ membranes from Orelis) were flat sheets made of a polyethersulfone (PES) skin layer on a polyester support layer. These PES membranes had a molecular weight cut-off of $10 \mathrm{kDa}$ and a surface area of $149.4 \mathrm{~cm}^{2}$. Filtration experiments were performed with a cross-flow system described in Figure 2. This membrane setup operated in a recycled mode. A contaminated aqueous solution $(2 \mathrm{~L})$ was added in the feed tank, and constantly pumped into the membrane module. The solution was filtered in a tangential mode under a trans-membrane pressure (TMP) of $0-3$ bars which was applied thanks to the retentate closing valve. The cross-flow velocity was $0.063 \mathrm{~m} \mathrm{~s}^{-1}$.

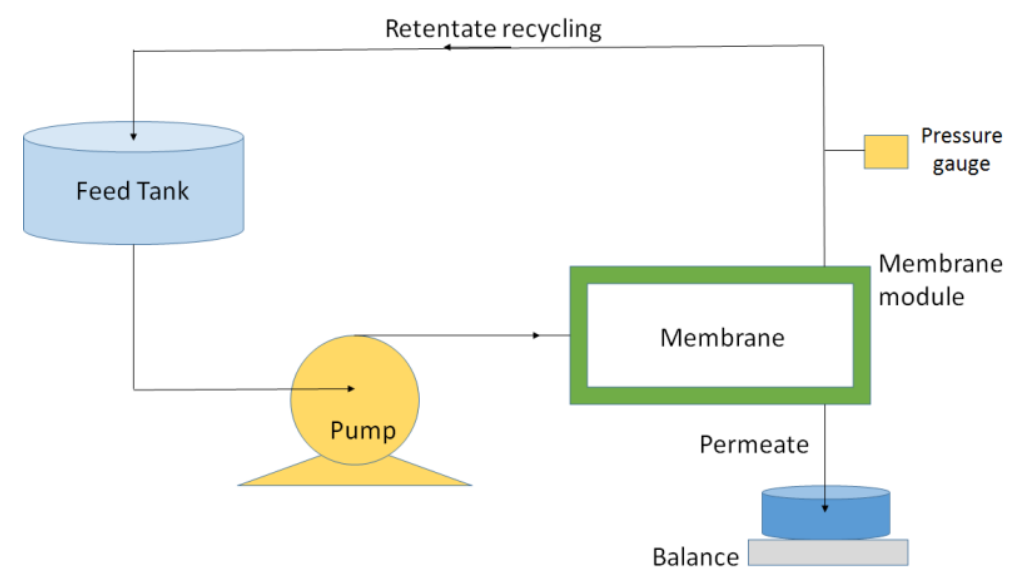

Figure 2. Schematic diagram of membrane filtration setup.

At a pressure of 2 bars, a few milliliters of permeate was collected after 20 min of pumping (to stabilize the flux), for being analyzed by atomic absorption spectrometry. Before being used for the first time, the membrane was immersed in a $10^{-2} \mathrm{~mol} \mathrm{~L}-1 \mathrm{NaOH}$ solution for $2 \mathrm{~h}$, rinsed with water, and stored in water overnight (to remove the chemicals remaining from the manufacturing process). Between each experiment, the membrane was cleaned by circulating a $10^{-2} \mathrm{~mol} \mathrm{~L}^{-1} \mathrm{NaOH}$ solution for $30 \mathrm{~min}$ without applying a TMP pressure and $10 \mathrm{~min}$ with a TMP pressure of 2 bars, followed by rinsing with water (several times, with TMP pressure at 2 bars) to remove the polymer film and to restore the water flux and the membrane permeability. The same cleaning operations were repeated until recovering the initial water flux and membrane permeability.

After a night in pure water, the permeability was determined. Then, the membrane was modified using the Layer-by-Layer (LbL) technique which involves the sequential deposition on a substrate of two species interacting spontaneously. The most common type of LbL assembly is based on alternating deposition of polyanions and polycations leading to thin polyelectrolyte multilayer films, as first reported by Decher [40]. Here, this technique was used to deposit a multilayer film composed of 
poly(styrene sulfonate) (PSS) as polyanion and poly(allylamine hydrochloride) (PAH) as polycation on the PES membrane surface. Since the PES membrane was negatively charged [41], it was first immersed into the positively charged $\mathrm{PAH}$ polycation solution $\left(\mathrm{pH}_{\mathrm{PAH}}=3.9<\mathrm{pKa} \mathrm{PAH}=8.8\right)$ for $30 \mathrm{~min}$, followed by rinsing with deionized water. Next, the membrane was immersed into the negatively charged PSS polyanion solution $\left(\mathrm{pH}_{\mathrm{PSS}}=4.8>\mathrm{pKaPSS}=1.5\right)$ for $30 \mathrm{~min}$ and rinsed; thus, a $\mathrm{PAH} / \mathrm{PSS}$ bilayer film was obtained. Following this procedure, a multilayer film made of 11 successive polyelectrolyte layers was self-assembled by repeating the PAH and PSS deposition cycles. Such number of polyelectrolyte layers was chosen since it leads to optimal metal ions removal, as previously shown by our group [17].

\subsection{Preparation of the $\mathrm{SiO}_{2}$-CMCS Hybrid Materials}

Aerosil 200 fumed silica was dried in an oven at $100^{\circ} \mathrm{C}$, crushed and kept in a desiccator until use. Carboxymethyl chitosan (CMCS, Figure 3a) was prepared by reaction of chitosan with chloroacetic acid in a basic medium following the synthesis protocol developed by Liang et al. [42]. Two grams of the so-obtained CMCS powder were then added to $100 \mathrm{~mL}$ of deionized water, and the suspension was stirred during $24 \mathrm{~h}$ to allow the complete dissolution of the CMCS powder. After that, $0.5 \mathrm{~g}$ of Aerosil 200 silica was added to $100 \mathrm{~mL}$ of the CMCS solution. The suspension was stirred during $24 \mathrm{~h}$

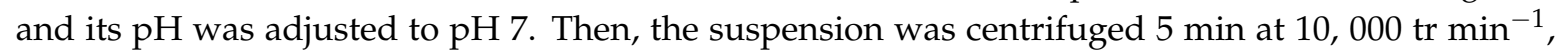
and rinsed with water. The procedure was repeated until the conductivity reached a value inferior to $100 \mu \mathrm{S} \mathrm{cm}{ }^{-1}$. Then, the composite was dried in an oven at $110{ }^{\circ} \mathrm{C}$ during $24 \mathrm{~h}$, crushed to obtain a brown powder and kept in a desiccator until use. This protocol allowed the encapsulation of the colloidal silica by the CMCS reactant.

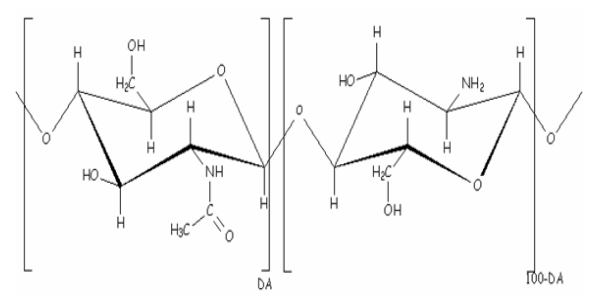

(a)

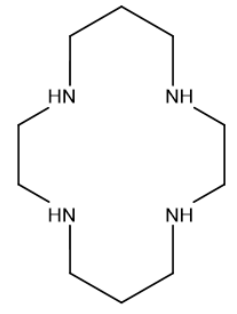

(b)

Figure 3. Structures of: (a) carboxymethyl chitosan (CMCS); and (b) tetraazamacrocycle cyclam.

In previous works, these composites were characterized. Thus, the specific surface area of the silica particles decreased considerably after modification since it decreased from $200 \mathrm{~m}^{2} \mathrm{~g}^{-1}$ to $5 \mathrm{~m}^{2}$ $\mathrm{g}^{-1}$ [32]. The degree of ionization of the carboxyl groups of these composites was determined and found to be 0.74 using titration experiments and the isoelectric point of $\mathrm{SiO}_{2}-\mathrm{CMCS}$ composite was found to be 6.0 using zeta-potential measurements [43]. The morphology of $\mathrm{SiO}_{2}$-cyclam composites was also studied and it was found by SEM that these composites consist in small grains of the silica particles distributed heterogeneously in the CMCS matrix. The infrared and ${ }^{1} \mathrm{H}$ RMN spectra of $\mathrm{SiO}_{2}-\mathrm{CMCS}$ composites can also be found elsewhere $[19,43]$.

\subsection{Preparation of the $\mathrm{SiO}_{2}$-Cyclam Hybrid Materials}

The first part of the synthesis consists in the preparation of pre-functionalized (mesoporous silica matrix)-Cl. In this aim, triblock copolymer $\left(\mathrm{EO}_{20} \mathrm{PO}_{70} \mathrm{EO}_{20}\right.$ with $\mathrm{PEO}=$ poly(ethylene oxide) and PPO $=$ poly(propylene oxide)) Pluronic P123 (4.0 g) was dissolved in $160 \mathrm{~mL}$ of an aqueous solution of $\mathrm{HCl}$ $(\mathrm{pH}=1.5)$. The resulting clear solution was added to a mixture of 3-chloropropyltrimethoxysilane $(0.84 \mathrm{~g}, 4.49 \mathrm{mmol})$ and tetraethylorthosilicate (TEOS) $(8.41 \mathrm{~g}, 40.41 \mathrm{mmol})$. A vigorous stirring was performed for $3 \mathrm{~h}$ at room temperature until a transparent solution appeared.

Then, the solution was transferred in a hot oil bath at $60{ }^{\circ} \mathrm{C}$ and $\mathrm{NaF}(76.0 \mathrm{mg}, 1.80 \mathrm{mmol})$ was immediately added to induce the polycondensation. A white precipitate appeared within a few 
minutes and the resulting suspension was further stirred for 2 days at $60{ }^{\circ} \mathrm{C}$. The resulting white powder was filtered off and the surfactant was selectively removed by soxhlet extraction over ethanol for $24 \mathrm{~h}$. After drying at $120^{\circ} \mathrm{C}$ overnight under vacuum, $2.89 \mathrm{~g} \mathrm{(94 \% )}$ of a white powder were obtained. This powder (called Silica-Cl) consisted of mesoporous silica bearing $\left(\mathrm{CH}_{2}\right)_{n}$ - $\mathrm{Cl}$ chains which were used later to attach the functionalizing cyclam groups.

The second step was the immobilization of cyclam groups on mesoporous silica. The process used a mixture of 1,4,8,11-tetraazacyclotetradecane (cyclam) $(0.42 \mathrm{~g}, 2.09 \mathrm{mmol})$, Silica-Cl (1.00 g, $1.49 \mathrm{mmol})$ dissolved in $90 \mathrm{~mL}$ of acetonitrile and triethylamine $(1.1 \mathrm{~g}, 10.9 \mathrm{mmol})$. The used mixture was heated under reflux $\left(78^{\circ} \mathrm{C}\right)$ and stirred for 2 days. The white solid was quantitatively recovered by filtration and washed five times with hot chloroform and three times with hot ethanol to remove the excess of cyclam. After drying at $120^{\circ} \mathrm{C}$ overnight under vacuum, $1.10 \mathrm{~g}(95 \%)$ of mesoporous silica functionalized by cyclam molecules (Silica-cyclam) were obtained as a white powder.

Some properties of the mesoporous $\mathrm{SiO}_{2}$-cyclam composites were determined: specific surface areas were determined by Brunauer-Emmett-Teller (BET) method on an ASAP 2010 analyser (Micromeritics, Norcross, GA, USA) and the average pore diameters were calculated by the BJH method. The BET surface area was $S_{B E T}=627 \mathrm{~m}^{2} \mathrm{~g}^{-1}$, the total pore volume was $V_{p}=0.52 \mathrm{~cm}^{3} \mathrm{~g}^{-1}$, the mean pore diameter was $D_{p}=36 \AA$, and the mean thickness of the pore walls was $70 \AA$. The structure of $\mathrm{SiO}_{2}$-cyclam is very porous and consists of parallel and well-aligned pores as previously shown by TEM [44]. The infrared and Raman spectra of $\mathrm{SiO}_{2}$-cyclam composites can also be found elsewhere [44].

\subsection{Adsorption Experiments}

The adsorption of $\mathrm{Ni}(\mathrm{II}), \mathrm{Cu}(\mathrm{II})$ and $\mathrm{Zn}(\mathrm{II})$ ions by cyclam- and CMCS-modified silica materials was carried out at room temperature to determine their respective adsorption capacity. To quantify the adsorption capacities of the hybrid materials, series of $\mathrm{Ni}$ (II), $\mathrm{Cu}$ (II) and $\mathrm{Zn}$ (II) solutions, with an initial concentration between 1 and $1000 \mathrm{mg} \mathrm{L}^{-1}$, were prepared in plastic bottles and the initial $\mathrm{pH}$ of the solution was adjusted to $\mathrm{pH} 5$. A pH of 5 was chosen to prevent the precipitation of metal cations. Moreover, the effect of $\mathrm{pH}$ on the metal ion uptake of cyclam-modified polymeric microbeads was studied by Kavakli et al. [34] who demonstrated that $\mathrm{pH}$ values of 5-6 were more suitable than lower values to obtain a maximum uptake of all metal ions. After adjustment of the $\mathrm{pH}, 25 \mathrm{mg}$ of adsorbent were added in the metal solutions $(100 \mathrm{~mL})$, and the bottles containing the suspensions were sealed and kept under stirring during $24 \mathrm{~h}$.

Once the equilibrium reached, the equilibrium concentration $C_{e}$ was measured by atomic absorption spectrometry (AAS). It allowed to access to the concentration of adsorbed metal cations which is the initial metal concentration minus the equilibrium metal concentration $\left(C_{0}-C_{e}\right)$. From these values, it was possible to obtain the equilibrium adsorption capacity $q_{e}$ of each adsorbent which was calculated using Equation (1):

$$
q_{e}=\frac{\left(C_{0}-C_{e}\right) \times V}{W}
$$

where $q_{e}\left(\mathrm{mg} \mathrm{g}^{-1}\right)$ is the equilibrium adsorption capacity, $C_{0}$ and $C_{e}$ are the initial and equilibrium metal concentrations $\left(\mathrm{mg} \mathrm{L}^{-1}\right)$, respectively, $V$ is the volume of the metal solution $(\mathrm{L})$ and $W$ is the amount of the adsorbent $(\mathrm{g})$.

\subsection{Analytic Methods}

All the concentrations of $\mathrm{Ni}(\mathrm{II}), \mathrm{Cu}(\mathrm{II})$ and $\mathrm{Zn}(\mathrm{II})$ ions were determined by flame atomic absorption spectrometry using a SpectrAA 50B (Varian, Grenoble, France) using air/acetylene mixing (ratio 4:1). 
The retention rate $(R)$ which corresponds here to the contaminant removal efficiency was defined as the percentage of a contaminant removed from the feed solution by the membrane. It was deduced from the AAS analyses and calculated using Equation (2):

$$
R(\%)=\left(1-\frac{C_{P}}{C_{0}}\right) \times 100
$$

where $C_{0}\left(\mathrm{mg} \mathrm{L}^{-1}\right)$ is the initial concentration of metal cations in the feed, and $C_{P}\left(\mathrm{mg} \mathrm{L}^{-1}\right)$ is the same item in the permeate.

The permeate volume flux $\left(J_{V}\right)$ was calculated, using Equation (3), from the time taken to collect a few milliliters of a weighed permeate sample at each value of TMP and after $20 \mathrm{~min}$ of pumping (to stabilize the flux):

$$
J_{V}=\frac{m_{p}}{\rho \times S \times t}
$$

where $m_{p}, \rho, S$ and $t$ are the mass of the collected permeate sample (g), the volumetric mass of solution $\left(\mathrm{g} \mathrm{m}^{-3}\right)$, the effective area of the membrane $\left(\mathrm{m}^{2}\right)$ and the time (s), respectively.

Before any chemical modification, the permeability of the membrane was also determined by the same procedure using Equation (4):

$$
J_{w}=L_{p} \Delta P
$$

where $J_{W}, \Delta P$ and $L_{p}$ are the permeate flux for water $\left(\mathrm{m}^{3} \mathrm{~m}^{2} \mathrm{~s}^{-1}\right)$, the TMP (bar) and the permeability of the membrane $\left(\mathrm{m}^{3} \mathrm{~m}^{2} \mathrm{~s}^{-1} \mathrm{bar}^{-1}\right)$, respectively.

\section{Results}

\subsection{Adsorption of the Metal Ions by $\mathrm{SiO}_{2}-\mathrm{CMCS}$ and $\mathrm{SiO}_{2}$-Cyclam Adsorbents}

An adsorption isotherm is a curve describing the phenomenon governing the adsorption or retention of a substance to a solid-phase at a constant temperature and $\mathrm{pH}$. Thus, an adsorption isotherm can describe how pollutants, such as heavy metal cations, interact with the adsorbent materials. The physicochemical parameters and the thermodynamic assumptions of the adsorption model provide an insight into the adsorption mechanism of the adsorbates onto the adsorbents. Numerous equilibrium isotherm models based on different kinetic and thermodynamic approaches have been proposed over the years. The Freundlich adsorption model is an experimental model which is frequently used to study heterogeneous systems. Indeed, Freundlich isotherm describes non-ideal and reversible adsorption and is not restricted to monolayer formation. Thus, it considers that: (i) adsorption sites are not identical; (ii) the total adsorbed amount is summed over all types of sites; and (iii) energy distribution decays exponentially. In the field of metal removal, this model has been successfully used to describe the adsorption of metal ions on aminated adsorbents by Koong et al. [29]. Graphically, the plot of $\ln \left(q_{e}\right)$ versus $\ln \left(C_{e}\right)$ should indicate a straight line in the case of an adsorption following the Freundlich model [45]. Langmuir isotherm model is a more theoretical model which is very commonly used. It was initially formulated to describe gas-solid phase adsorption onto activated carbon. The Langmuir model assumes: (i) monolayer coverage of the solid; (ii) all adsorption sites are equally probable; and (iii) no interaction between adsorbed species even on adjacent sites. Graphically, it is characterized by a plateau, an equilibrium saturation point where, once a molecule occupies a site, no further adsorption can take place. This model has been successfully used to describe the adsorption of $\mathrm{Cd}(\mathrm{II}), \mathrm{Cr}(\mathrm{III})$ and $\mathrm{Co}$ (II) on functionalized $\mathrm{Fe}_{3} \mathrm{O}_{4}$ nanoparticles by Alqadami et al. [46].

However, in Figure 4, which shows the evolution of the equilibrium capacity per mass of the adsorbent $q_{e}$ as a function of the equilibrium copper concentration $\left(C_{e}\right)$ in solution for cyclam-modified silica (Figure 4a) and CMCS-modified silica (Figure 4b), the profile of the curves that we obtained when studying the adsorption of metal ions on modified adsorbents did not fit with the curve profiles of Langmuir and Freundlich isotherms. On the contrary, our curves fit very-well with the general curve 
profile of Brunauer-Emmet-Teller (BET) isotherms. Indeed, BET isotherm is a theoretical equation which was developed to derive multilayer adsorption systems. Thus, this is a more general multilayer model which assumes that a Langmuir isotherm is applied to each layer and that no transmigration occurs between the successive layers. It also assumes that there is equal energy of adsorption for each layer except for the first layer. Even if the BET isotherm is more frequently used to study the adsorption of gas on adsorbents, it is also possible to use it for studying the adsorption of a solute on the surface of an adsorbent. In this case, the BET isotherm is described by Equation (5) [47]:

$$
q_{e}=\frac{K_{B E T} C_{e} Q^{\circ}}{\left(C_{S}-C_{e}\right)\left\{1+\left(K_{B E T}-1\right)\left(C_{e} / C_{S}\right)\right\}}
$$

where $K_{B E T}\left(\mathrm{~L} \mathrm{mg}^{-1}\right)$ is an adsorption constant relating to the energy of interaction with surface, $C_{S}$ is the saturation concentration of the solute $\left(\mathrm{mg} \mathrm{L}^{-1}\right)$, and $Q^{\circ}\left(\mathrm{mg} \mathrm{g}^{-1}\right)$ is the maximum adsorption capacity for forming single layer.

(a)

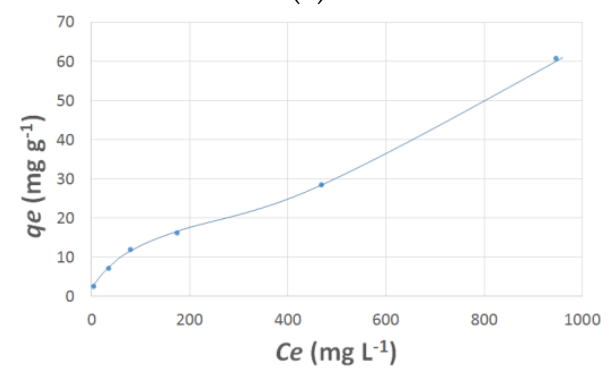

(a) (b)

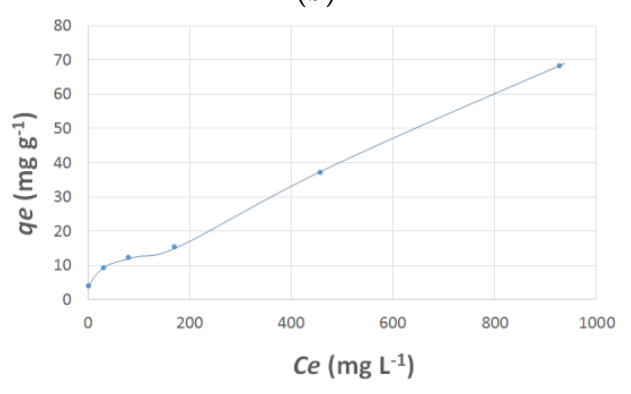

Figure 4. Equilibrium adsorption of $\mathrm{Cu}$ (II) with: (a) $\mathrm{SiO}_{2}$-cyclam; and (b) $\mathrm{SiO}_{2}-\mathrm{CMCS}$ hybrid materials.

Graphically, a BET isotherm is generally characterized by two domains: (i) a first domain at low concentration which is similar to the Langmuir isotherm since it consists in an increase followed by a plateau indicating that each site is occupied by a molecule (this plateau corresponds to the formation of the first layer of adsorbate); and (ii) a continuous increase which corresponds to the formation of the following adsorbate layers onto the first monolayer. However, depending on the value of the different parameters involved in Equation (5), the plateau can be more or less visible [48]. In Figure 4, which depicts the evolution of the amount of $\mathrm{Cu}(\mathrm{II})$ ions adsorbed $\left(q_{e}\right)$ versus the concentration of metal ions remaining in solution $\left(C_{e}\right)$, it is noticeable that there is no saturation of the $q_{e}$ values which would be characteristic of the adsorption of a monolayer according to Langmuir model. On the contrary, after an almost vertical increase at low concentrations, which corresponds to the very rapid monolayer formation on the adsorbent, the $q_{e}$ value increases with a smaller positive slope between 100 and $200 \mathrm{ppm}$. After that, at high concentrations, the $q_{e}$ value continuously increases as long as metal ions are present in solution. This part of the curve corresponds to the formation of the second and higher adsorbate layers obtained by adsorption of the metal ions. Since the curve profile corresponds very well with the BET model, this means that the adsorption of the $\mathrm{Cu}(\mathrm{II}), \mathrm{Ni}(\mathrm{III})$ and $\mathrm{Zn}$ (II) cations onto $\mathrm{SiO}_{2}-\mathrm{CMCS}$ and $\mathrm{SiO}_{2}$-cyclam particles is not limited to a monolayer but consists in a multilayer adsorption in which no transmigration takes place between the layers. It also means that each layer has the same energy of adsorption except the first one. The adsorption of the metal ions is due both to electrostatic interactions between cations and to complexation between the aminated adsorbates and the metal ions in presence of counter-anions. Indeed, complexation can occur between the adsorbent and the first layer of metal ions, but once the first layer is formed then there would be no such complexation anymore and after that it is possible to form another layer which will be positively charged. Thus, after this layer, no adsorption is expected as there is no complexation and due to electrostatic repulsion between cations. 
Looking at Figure $4 \mathrm{a}, \mathrm{b}$, it is possible to estimate the maximum of the adsorbent capacity $\left(q_{\max }\right)$ of $\mathrm{SiO}_{2}$-CMCS and $\mathrm{SiO}_{2}$-cyclam particles observed over the range of metal concentration going from 1 to $950 \mathrm{mg} \mathrm{L}^{-1}$ (since the curves are continuously increasing over this concentration range the $q_{\max }$ value was taken at $950 \mathrm{ppm}$ for all metals). Resulting values, gathered in Table 1, give the adsorption capacity of cyclam- and CMCS-based adsorbents for the different metal ions. It can be observed that CMCS-based adsorbents were slightly more efficient since the maximum of adsorption reached 68, 61 and $45 \mathrm{mg} \mathrm{g}^{-1}$ for $\mathrm{Cu}(\mathrm{II}), \mathrm{Ni}(\mathrm{II})$ and $\mathrm{Zn}(\mathrm{II})$ ions, respectively, with CMCS-based adsorbents while $\mathrm{q}_{\max }$ values were 61,50 and $26 \mathrm{mg} \mathrm{g}^{-1}$ for $\mathrm{Cu}(\mathrm{II}), \mathrm{Ni}(\mathrm{II})$ and $\mathrm{Zn}$ (II) ions, respectively, with cyclam-based adsorbents for an initial concentration of $950 \mathrm{mg} \mathrm{L}^{-1}$. However, these differences are not high enough to be really significant and one can conclude that both cyclam- and CMCS-modified materials both possess a very good adsorption capacity towards $\mathrm{Ni}(\mathrm{II}), \mathrm{Cu}(\mathrm{II})$ and $\mathrm{Zn}(\mathrm{II})$ metals. Indeed, the best adsorption capacities of cyclam-silica and CMCS-silica based adsorbents were 61 and $69 \mathrm{mg} \mathrm{g}^{-1}$ for $\mathrm{Cu}$ (II) ions, respectively, which constitute high capacities compared to the adsorption capacities for $\mathrm{Cu}$ (II) ions of other common adsorbents and hybrid materials as detailed in Section 4.1. For comparison of adsorbent performance, the monolayer adsorption capacity $\left(\mathrm{q}_{\mathrm{ML}}\right.$ ) was also calculated from the slopes of the linear plots of BET equation. The $\mathrm{q}_{\mathrm{ML}}$ values obtained for $\mathrm{SiO}_{2}-\mathrm{CMCS}$ composites were 18,15 and $9 \mathrm{mg} \mathrm{g}^{-1}$ for $\mathrm{Cu}(\mathrm{II}), \mathrm{Ni}(\mathrm{II})$ and $\mathrm{Zn}$ (II) ions, respectively. These values were higher than those obtained for $\mathrm{SiO}_{2}$-cyclam composites which were 16,13 and $6 \mathrm{mg} \mathrm{g}^{-1}$ for $\mathrm{Cu}(\mathrm{II}), \mathrm{Ni}(\mathrm{II})$ and $\mathrm{Zn}$ (II) ions, respectively. The interaction mechanism of metal ions with the adsorbents is also discussed in Section 4.2.

Table 1. Maximum equilibrium capacity of the adsorbent per mass $\left(q_{m}\right)$ for metal concentrations comprised between 1 and $1000 \mathrm{mg} \mathrm{L}^{-1}$.

\begin{tabular}{|c|c|c|}
\hline Metal Ion & $\mathrm{SiO}_{2}-\mathrm{Cyclam}$ Hybrid Material & $\mathrm{SiO}_{2}$-CMCS Hybrid Material \\
\hline $\mathrm{Cu}(\mathrm{II})$ & $q_{m}=61 \mathrm{mg} \mathrm{g}^{-1}$ & $q_{m}=68 \mathrm{mg} \mathrm{g}^{-1}$ \\
\hline $\mathrm{Ni}(\mathrm{II})$ & $q_{m}=50 \mathrm{mg} \mathrm{g}^{-1}$ & $q_{m}=61 \mathrm{mg} \mathrm{g}^{-1}$ \\
\hline $\mathrm{Zn}(\mathrm{II})$ & $q_{m}=26 \mathrm{mg} \mathrm{g}^{-1}$ & $q_{m}=45 \mathrm{mg} \mathrm{g}^{-1}$ \\
\hline
\end{tabular}

\subsection{Filtration-Adsorption Combined Process}

\subsubsection{Single Component Solutions}

To determine the ability of the modified membranes to remove heavy metal ions from a contaminated aqueous solution, the filtration experiments of metal ions were first performed with single salt solutions in the form of copper (II), zinc (II) and nickel (II) chloride. Moreover, it is important to perform these filtrations with different initial metal concentrations in the feed to assess the range of applicability of the filtration process. That is why the removal of metal ions by PAH-PSS modified membranes was investigated by carrying out retention experiments for $\mathrm{pH} 5$ feed solutions over a wide concentration range (50-1200 $\mathrm{mg} \mathrm{L}^{-1}$ ). At the lowest initial concentration, the combined treatment was so efficient $(R>90 \%)$ that it is difficult to discuss the impact of the experimental parameters. That is why we have also worked on metal concentrations as high as $1200 \mathrm{mg} \mathrm{L}^{-1}$. The observed metal retention rates for the different metal solutions were plotted against concentration in Figure 5.

When metal ions solutions were treated using the modified-membranes, the retention rate of $\mathrm{Cu}(\mathrm{II}), \mathrm{Ni}(\mathrm{II})$ and $\mathrm{Zn}(\mathrm{II})$ reached $91 \%, 93 \%$ and $98 \%$, respectively, for an initial feed concentration of $50 \mathrm{mg} \mathrm{L}^{-1}$ which was the lowest concentration tested, but already constitutes a high concentration for an effluent solution. Logically, when the metal concentration was increased, the retention rate of all metal ions decreased since the chelating functions of the polymer film were unable to chelate all metal cations present in the solutions. However, even at very high concentration $\left(1200 \mathrm{mg} \mathrm{L}^{-1}\right)$, the retention rate remained not negligible since it was comprised between $62 \%$ and $67 \%$ whatever the metal ion (Figure 5). The evolution of the retention rate as a function of the metal concentration was similar for the three metal ions used even if it can be observed that the retention rates obtained for 
$\mathrm{Ni}(\mathrm{II})$ ions were slightly lower than those obtained for $\mathrm{Cu}(\mathrm{II})$ and $\mathrm{Zn}(\mathrm{II})$ ions. It is also noteworthy that unmodified PES membranes were not able to efficiently retain metal ions since the retention rate obtained with unmodified membranes was lower than $5 \%$ whatever the nature and concentration of the metal ion.

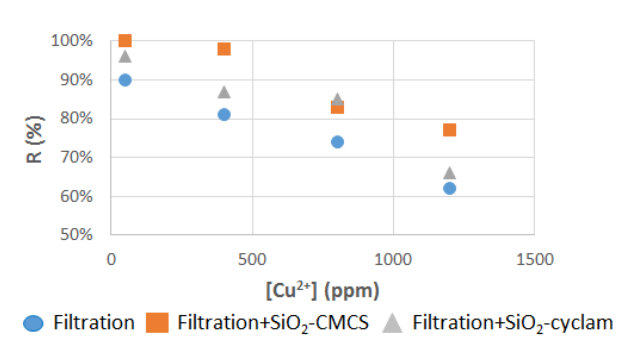

(a)

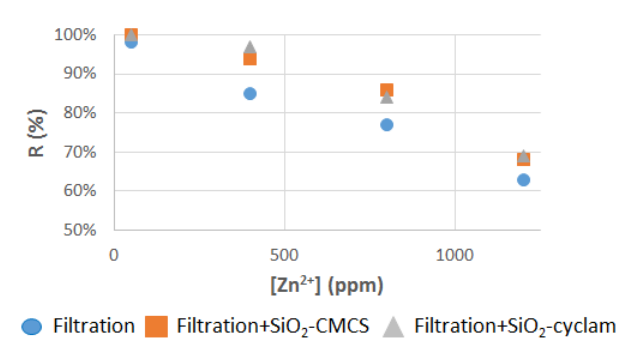

(c)

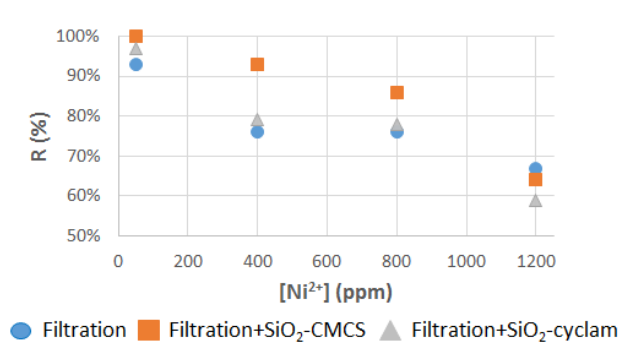

(b)

Figure 5. Retention rates ( $\mathrm{R} \%$ ) of the single metal ion solutions at different concentrations with or without use of an adsorbent: (a) Cu(II) solution; (b) Ni(II) solution; and (c) Zn(II) solution.

After filtration through the modified membranes, the permeate solutions were recovered. At this point of the process, these solutions still contained heavy metal ions. Indeed, a feed solution initially concentrated at $1200 \mathrm{mg} \mathrm{L}^{-1}$ and leading to a retention rate of $70 \%$ still contained $360 \mathrm{mg} \mathrm{L}^{-1}$ of metal ions. To remove these persisting metal ions, $25 \mathrm{mg}$ of adsorbent $\left(\mathrm{SiO}_{2}\right.$-cyclam or $\left.\mathrm{SiO}_{2}-\mathrm{CMCS}\right)$ was added into the previously filtered solutions $(100 \mathrm{~mL})$. The aim of the adsorbent addition was to determine the efficiency of the combination filtration/adsorption by measuring the metal retention rate before and after the addition of silica hybrid materials used as adsorbents.

As expected, the addition of silica hybrid materials allowed the adsorption of some persisting metal ions by the adsorbent, and thus resulted in an increase of the removal efficiency of the process. For example, in the case of the adsorption of copper ions by cyclam-modified silica, the retention rate increased from $91 \%$ to $97 \%$ at low concentration $\left(50 \mathrm{mg} \mathrm{L}^{-1}\right.$ ) and from $62 \%$ to $67 \%$ at high concentration (1200 mg L ${ }^{-1}$ ). Similarly, the retention rate increased from $91 \%$ to $100 \%$ at low concentration and from $62 \%$ to $77 \%$ at high concentration when $\mathrm{SiO}_{2}-\mathrm{CMCS}$ was used as adsorbent to remove copper ions (Figure 5). Thus, both adsorbents allowed the removal of part of the metal ions in solution but $\mathrm{SiO}_{2}$-CMCS materials had a stronger efficiency than $\mathrm{SiO}_{2}$-cyclam to uptake $\mathrm{Cu}$ (II) ions. With $\mathrm{Ni}$ (II) and $\mathrm{Zn}$ (II) solutions, a similar increase of the removal efficiency was observed any metal concentration and for any nature of the adsorbent. Indeed, both adsorbents had nearly the same removal efficiency. For example, at low concentration, the $\mathrm{Zn}$ (II) retention rate increased from $98 \%$ without adsorbent to $100 \%$ with $\mathrm{SiO}_{2}$-cyclam or with $\mathrm{SiO}_{2}$-CMCS adsorbent, while, at high concentration, it increased from $63 \%$ to $68-69 \%$, whichever adsorbent was used.

The interaction mechanism of metal ions with modified membranes is discussed in Section 4.3.

\subsubsection{Multicomponent Solutions}

Before adding adsorbents in the poly-contaminated solutions, the performances of the modified membranes were first studied using mixed salt solutions. Feed solutions containing copper, zinc and 
nickel chloride ions were prepared. The initial total metal ions concentrations of these solutions were $50,400,800$ or $1200 \mathrm{mg} \mathrm{L}^{-1}$. For example, the solution concentrated at $1200 \mathrm{mg} \mathrm{L}^{-1}$ contained $400 \mathrm{mg} \mathrm{L}^{-1}$ of $\mathrm{Cu}(\mathrm{II}), 400 \mathrm{mg} \mathrm{L}^{-1}$ of $\mathrm{Zn}$ (II) and $400 \mathrm{mg} \mathrm{L}^{-1}$ of $\mathrm{Ni}(\mathrm{II})$ ions.

First, it can be observed that the retention rate of the metal ions in the multicomponent solutions was very similar to the one obtained with single component solutions. For example, the retention rates of $\mathrm{Cu}$ (II) ions in copper solutions were $90 \%, 81 \%, 74 \%$ and $62 \%$ at 50, 400, 800 and $1200 \mathrm{mg} \mathrm{L}^{-1}$, respectively, when the retention rates of $\mathrm{Cu}$ (II) ions in multicomponent solutions were $93 \%, 86 \%$, $75 \%$ and $66 \%$, respectively, at the same concentrations (Figure 6). It can also be observed that there were no significant differences between the retention rates of the different metals present in the multicomponent solutions. For example, at low concentration $\left(50 \mathrm{mg} \mathrm{L}^{-1}\right)$, the retention rates of $\mathrm{Cu}$ (II), $\mathrm{Ni}(\mathrm{II})$ and $\mathrm{Zn}$ (II) were $93 \%, 95 \%$ and $92 \%$, respectively. Similarly, at high concentration $\left(1200 \mathrm{mg} \mathrm{L}^{-1}\right)$, the retention rates of $\mathrm{Cu}(\mathrm{II}), \mathrm{Ni}(\mathrm{II})$ and $\mathrm{Zn}(\mathrm{II})$ were $66 \%, 70 \%$ and $63 \%$, respectively. Except at very high concentrations, these retention rates are high enough to conclude that the removal of the three metal ions from a multicomponent solution is possible using modified membranes.

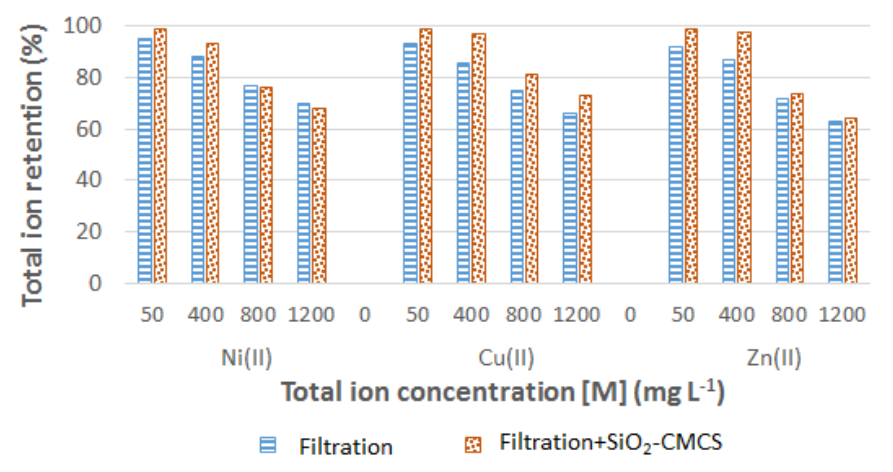

Figure 6. Ion retention (\%) of mixed metal ion solutions at different concentrations with or without use of $\mathrm{SiO}_{2}-\mathrm{CMCS}$ adsorbent $\left(\left[\mathrm{Ni}^{2+}\right]=\left[\mathrm{Cu}^{2+}\right]=\left[\mathrm{Zn}^{2+}\right]=[\mathrm{M}]_{\mathrm{tot}} / 3\right)$.

To estimate the usefulness of combining filtration and adsorption for removing metal ions from poly-contaminated solutions, we then added $25 \mathrm{mg}$ of adsorbent to the permeate solutions $(100 \mathrm{~mL})$ collected after filtration through the modified membranes. Once the adsorption equilibrium reached, the solutions were analyzed to determine the removal efficiency at this end of the filtration/adsorption process. The so-obtained values are summarized in Figure $6\left(\mathrm{SiO}_{2}-\mathrm{CMCS}\right.$ adsorbent) and Figure 7 ( $\mathrm{SiO}_{2}$-cyclam adsorbent).

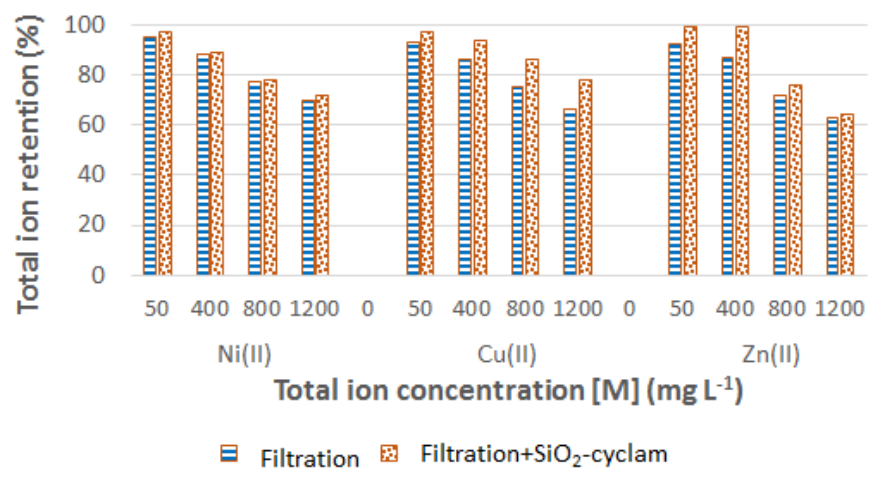

Figure 7. Ion retention (\%) of mixed metal ion solutions at different concentrations with or without use of $\mathrm{SiO}_{2}$-cyclam adsorbent $\left(\left[\mathrm{Ni}^{2+}\right]=\left[\mathrm{Cu}^{2+}\right]=\left[\mathrm{Zn}^{2+}\right]=[\mathrm{M}]_{\text {tot }} / 3\right)$.

Not surprisingly, the addition of adsorbent resulted in an increase of the removal efficiency whatever the metal ion and its initial concentration. For example, the use of $\mathrm{SiO}_{2}$-cyclam adsorbent to uptake $\mathrm{Cu}$ (II) ions allowed an increase of the retention rate from $93 \%$ to $97 \%$ at $50 \mathrm{mg} \mathrm{L}^{-1}$, from $86 \%$ 
to $94 \%$ at $400 \mathrm{mg} \mathrm{L}^{-1}$, from $75 \%$ to $86 \%$ at $800 \mathrm{mg} \mathrm{L}^{-1}$, and from $66 \%$ to $78 \%$ at $1200 \mathrm{mg} \mathrm{L}^{-1}$. It is also noticeable that the use of $\mathrm{SiO}_{2}$-cyclam adsorbent allowed obtaining very high retention rates at low concentration ( $50 \mathrm{mg} \mathrm{L}^{-1}$ ): $97 \%$ of $\mathrm{Ni}(\mathrm{II}), 97 \%$ for $\mathrm{Cu}(\mathrm{II})$ and $99 \%$ for $\mathrm{Zn}(\mathrm{II})$, compared to $95 \%, 93 \%$ and $92 \%$, respectively, without the use of this adsorbent. The retention rates at very high concentration of $1200 \mathrm{mg} \mathrm{L}^{-1}$ were logically lower than the retention rates obtained at lower concentrations due to the difficulty of capturing such high quantity of metal ions but they reached interesting values of $72 \%$ and $78 \%$ for $\mathrm{Ni}(\mathrm{II})$ and $\mathrm{Cu}(\mathrm{II})$, respectively. The retention rate of $\mathrm{Zn}(\mathrm{II})$ was lower $(64 \%)$, probably because the adsorbent is more efficient for removing $\mathrm{Cu}(\mathrm{II})$ and $\mathrm{Ni}(\mathrm{II})$ ions than $\mathrm{Zn}$ (II) ions, as previously shown in Section 3.1.

Similar trends were obtained with $\mathrm{SiO}_{2}-\mathrm{CMCS}$ adsorbent. Indeed, the use of $\mathrm{SiO}_{2}-\mathrm{CMCS}$ allowed an increase of the retention rate of $\mathrm{Cu}$ (II) from $93 \%$ to $99 \%$ at $50 \mathrm{mg} \mathrm{L}^{-1}$, from $86 \%$ to $97 \%$ at $400 \mathrm{mg}$ $\mathrm{L}^{-1}$, from $75 \%$ to $81 \%$ at $800 \mathrm{mg} \mathrm{L}^{-1}$, and from $66 \%$ to $73 \%$ at $1200 \mathrm{mg} \mathrm{L}^{-1}$. Whatever the metal ion, the retention rate obtained at $50 \mathrm{mg} \mathrm{L}^{-1}$ was very high since it reached $99 \%$ for $\mathrm{Ni}$ (II), $\mathrm{Cu}$ (II) and $\mathrm{Zn}$ (II) ions. At the very high concentration of $1200 \mathrm{mg} \mathrm{L}^{-1}$, the retention rate of $\mathrm{Cu}$ (II) reached $73 \%$ but it was only $68 \%$ and $64 \%$ for $\mathrm{Ni}(\mathrm{II})$ and $\mathrm{Zn}(\mathrm{II})$ ions, respectively. Once again, this can be explained by the higher adsorption capacity of $\mathrm{SiO}_{2}-\mathrm{CMCS}$ towards $\mathrm{Cu}$ (II) than towards $\mathrm{Ni}$ (II) and $\mathrm{Zn}$ (II) ions.

In conclusion, at low metal concentration, the amount of adsorbent $\left(\mathrm{SiO}_{2}\right.$-cyclam or $\left.\mathrm{SiO}_{2}-\mathrm{CMCS}\right)$ was high enough to provide enough adsorption sites to metal cations, leading to very high retention rate whatever the metal ion. On the contrary, at high metal concentration, there were not enough adsorption sites on modified-silica particles to adsorb all metal cations, and thus a competition occurred among the metal cations for the available adsorption sites.

\section{Discussion}

\subsection{Comparison with Other Works}

As shown in Section 3.1., the best adsorption capacities of $\mathrm{SiO}_{2}$-cyclam and $\mathrm{SiO}_{2}-\mathrm{CMCS}$ adsorbents were 61 and $69 \mathrm{mg} \mathrm{g}^{-1}$ for $\mathrm{Cu}$ (II) ions, respectively. These values can be compared with the ones obtained in other works (Table 2). Thus, the adsorption capacities values are high compared to the ones of traditional adsorbents such as activated carbon (between 9 and $38 \mathrm{mg} \mathrm{g}^{-1}$, depending on the activated carbon used) [49,50], zeolites $\left(1-25 \mathrm{mg} \mathrm{g}^{-1}\right)$ or clays $\left(3-11 \mathrm{mg} \mathrm{g}^{-1}\right)$ [51]. Our values are also higher than those obtained with modified cellulose $\left(19-75 \mathrm{mg} \mathrm{g}^{-1}\right)$ [52] or with other mesoporous materials modified with similar organic compounds such as aminopropyl-MCM-41 (31 mg g $\left.{ }^{-1}\right)$ [53], mercaptopropyl-functional porous silica $\left(31 \mathrm{mg} \mathrm{g}^{-1}\right)$ [54], or EDTA-modified SBA-15 $\left(13 \mathrm{mg} \mathrm{g}^{-1}\right)$ [55]. Only other chitosan derivatives have already led to higher adsorption capacities towards $\mathrm{Cu}(\mathrm{II})$ ions (up to $222 \mathrm{mg} \mathrm{g}^{-1}$ ) [56,57]. In addition, it can be noticed that Escoda et al. previously showed that bare silica particles could not remove efficiently metal ions from aqueous solutions [58], which means that the efficiency of the adsorption observed in this work is unambiguously due to the presence of CMCS and cyclam on the silica particles.

Table 2. Maximum equilibrium capacity per mass $\left(q_{m}\right)$ of different adsorbent for copper (II).

\begin{tabular}{ccc}
\hline Adsorbent & $\boldsymbol{q}_{\boldsymbol{m}}\left(\mathbf{m g ~ g}^{\mathbf{- 1}}\right)$ & References \\
\hline $\mathrm{SiO}_{2}$-cyclam & 61 & This work \\
$\mathrm{SiO}_{2}$-CMCS & 68 & This work \\
Activated carbon & $9-38$ & {$[49,50]$} \\
Zeolite & $1-25$ & {$[51]$} \\
Clays & $3-11$ & {$[51]$} \\
Modified cellulose & $19-75$ & {$[52]$} \\
Aminopropyl-MCM-41 & 31 & {$[53]$} \\
Mercaptopropyl-silica & 13 & {$[54]$} \\
EDTA-modified SBA-15 & 13 & {$[55]$} \\
Chitosan & $4-222$ & {$[56,57]$} \\
\hline
\end{tabular}




\subsection{Interaction Mechanism of Metal Ions with the Adsorbents}

Both $\mathrm{SiO}_{2}$-CMCS and $\mathrm{SiO}_{2}$-cyclam adsorbents have some functional groups on their surface which interact with the metallic adsorbates. Thus, the adsorption ability of these adsorbents for $\mathrm{Cu}$ (II), $\mathrm{Zn}(\mathrm{II})$ and $\mathrm{Ni}(\mathrm{II})$ metal ions can be attributed to several mechanisms including complexation reactions and the electrostatic interaction between metal ions and amino groups. Indeed, it is well-known that amino groups are electron rich and metal ions are electropositive. Thus, $\mathrm{Cu}$ (II), $\mathrm{Zn}$ (II) and Ni(II) cations can easily attach with the amino groups of the adsorbents. In particular, the uptake of the selected metallic cations using $\mathrm{SiO}_{2}-\mathrm{CMCS}$ is mainly coordinated via the chelation of metal cations with amino groups of the chitosan [59], as follows:

$$
\mathrm{M}^{\mathrm{n}+}+\mathrm{x} \mathrm{RNH}_{2} \rightarrow \mathrm{M}\left(\mathrm{RNH}_{2}\right)_{\mathrm{x}}^{\mathrm{n}+}
$$

In addition, the carboxyl and hydroxyl groups present on the adsorbent can impact the adsorption mechanism. Indeed, previous studies have evidenced that two hydroxyl groups and one amino group can capture a divalent metal cation, whereas the fourth site of the cation is occupied by another hydroxyl group or by a water molecule [60].

It is also noteworthy that both cyclam- and CMCS-based adsorbents have a higher affinity towards the metal cations in the order of $\mathrm{Cu}(\mathrm{II})>\mathrm{Ni}(\mathrm{II})>\mathrm{Zn}$ (II). This is completely coherent with the results of other studies in which the same affinity order was observed. Thus, N-propylsalicylaldimino-functionalized SBA-15 mesoporous silica were prepared by Mureseanu et al. and used for the adsorption of $\mathrm{Ni}(\mathrm{II}), \mathrm{Cu}(\mathrm{II}), \mathrm{Co}$.(II) and $\mathrm{Zn}$ (II) ions from aqueous solutions [61]. They showed a higher adsorption capacity for $\mathrm{Cu}(\mathrm{II})$ ions than for the other metal ions and the adsorbent affinity for different ions decreased in the order: $\mathrm{Cu}$ (II) $>\mathrm{Ni}$ (II) $>\mathrm{Co}$.(II) $>\mathrm{Zn}$ (II). These results were related to the formation constants $\left(\mathrm{K}_{\mathrm{f}}\right)$ of the metal ion-ligand complexes since the bond strength between a ligand and a series of metal cations depends on the $\mathrm{K}_{\mathrm{f}}$ parameter according to the Irving-Williams series [62]. For the metal ions studied, the $\mathrm{K}_{\mathrm{f}}$ values and implicitly the bond strength between the metal ion and the ligand decrease in the following order: $\mathrm{Cu}$ (II) $>\mathrm{Ni}$ (II) $>\mathrm{Co}$.(II) $>\mathrm{Zn}(\mathrm{II})$.

Similarly, the competitive adsorption of $\mathrm{Cu}(\mathrm{II}), \mathrm{Ni}(\mathrm{II})$ and $\mathrm{Zn}(\mathrm{II})$ from polymetallic solutions onto glutaraldehyde cross-linked chitosan beads was studied by Juang et al. [47]. They showed a greater affinity of chitosan-modified beads for $\mathrm{Cu}$ (II) than for other metal ions. They also confirmed that the uptake of such transition metals is mainly effected via coordination with the amino groups on chitosan even if a second interaction is present between copper ions and the hydroxyl group of chitosan playing an additional role in the adsorption mechanism [63]. Consequently, the adsorption selectivity is believed to be governed by the strength of stability constants between the functional groups of adsorbents and the metal ions since the adsorption is due to the formation of complex by chelation between carboxylate and nitrogen-containing groups and metal ions. The higher affinity for $\mathrm{Cu}$ (II) than for other metal ions confirms this hypothesis since $\mathrm{Cu}$ (II) has a higher stability constant than $\mathrm{Ni}(\mathrm{II})$ or $\mathrm{Zn}$ (II) regardless of the type of ligand. Therefore, it is believed that $\mathrm{Cu}$ (II) ions interact stronger with the surface amino groups of chitosan than with the other metals [64].

The order of affinity of cyclam-based materials for $\mathrm{Cu}(\mathrm{II})$ and other metal ions is similar to the one observed with chitosan. Indeed, poly(p-chloromethyl styrene-ethyleneglycol dimethacrylate) polymeric microbeads carrying specific 1,4,8,11-tetraazacyclotetradecane ligand to metal ions were used for adsorption/desorption of metal ions from aqueous solutions [34]. The uptake of metal ions onto the modified microbeads was found to be high (more than $100 \mathrm{mg} \mathrm{g}^{-1}$ for initial metal concentration comprised between 0.05 and $20 \times 10^{-3} \mathrm{~mol} \mathrm{~L}^{-1}$ ) and partially selective since the cyclam-modified polymeric microbeads showed affinity to the studied metal ions in the order of $\mathrm{Cu}$ (II) $>\mathrm{Ni}$ (II) $>$ Co.(II) $>\mathrm{Zn}$ (II). This selectivity was attributed to differences of the cavity size of the ligand, solvated metal ion diameter, and complex stability between the amine group on the ligand and the metal ions. 


\subsection{Interaction Mechanism of Metal Ions with the Membranes}

The retention of metal ions by the modified membranes is due to three concomitant actions: the electrostatic interactions between membranes and cations, the complexation of the cations by the polymers deposited onto the membrane surface and the steric effect due to the partial filling of the membrane's pores by the polymer films (Figure 8). To better understand the mechanisms underlying the retention of the metals by the modified membranes, it is possible to look at each of this contribution more closely.

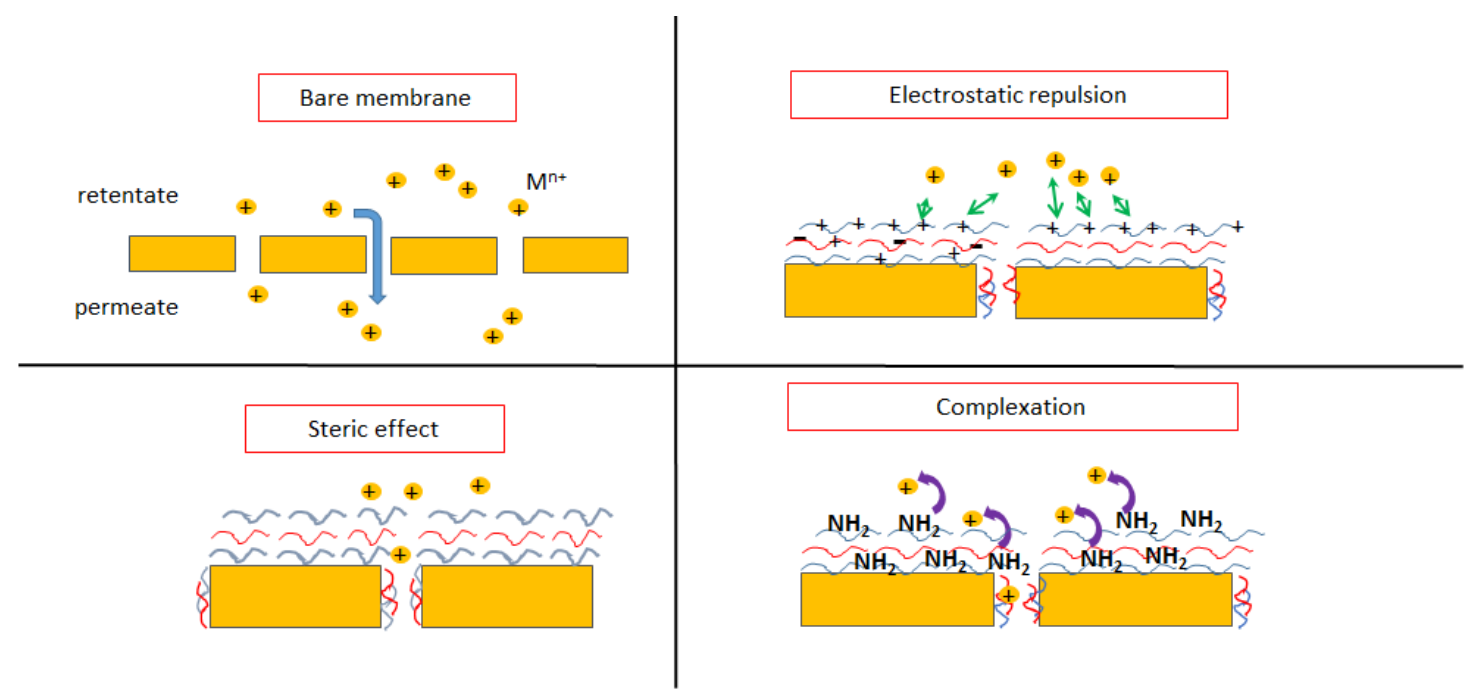

Figure 8. Schematic representation of the contributions impacting the retention of the metal ions.

The electrostatic contribution comes from the repulsion between the positively charged metal ions and the membrane surface which is positively charged since it is coated by a polymer multilayer film terminated by a polycation layer. Consequently, the metal cations are repelled by the membrane, the counter-anions being also retained because of electroneutrality requirements, leading to high retention rates of the metals. In previous works, we have shown using tangential streaming potential measurements that the zeta potential of the outer surfaces of PAH/PSS assemblies alternates, after each new PAH or PSS adsorption, becoming successively positive or negative [18]. In addition, membrane potential measurements evidenced that the charge of the walls of the membrane's pores alternates between positive and negative values, depending on the cationic or anionic nature of the last deposited polyelectrolyte layer [41]. Since the PAH/PSS films assembled in this paper are terminated by a cationic PAH film, the surface of the modified film is positive, thus leading to repulsive interactions between the modified membrane and the metal cations. Such mechanism was also observed by Gherasim et al. who studied the retention of cobalt ions by an organic tubular membrane [11]. In addition, we have already shown in previous studies that: (i) the retention of copper ions by a polymer-based modified membrane increases when the charge of the polycation increases and/or the charge of the polyanion decreases, thus indicating a strong influence of the polymer film's charge [17]; and (ii) the retention rate of a polymer-modified membrane is far higher when the multilayer film is terminated by a polycation layer than when it is terminated by a polyanion layer [18]. Considering all of this evidence, electrostatic effects are believed to be the phenomenon having the most important impact on the retention of the cations by the membrane.

The removal of metal ions is also influenced by steric effects. Indeed, an increase of the thickness of the polymer film induces a decrease of the membrane's pore size since the polymer film is deposited not only onto the surface of the membranes but also onto the walls of the pores. This decrease of the pore size of the pores is attested by the decline of the flux after chemical modification of the membrane 
(the flux is ten times higher before than after modification of the membrane by the polymer film). Thus, steric effects also play a role on the retention of metal ions by the modified membranes.

The chelation of metal ions by the membranes must also be considered. Indeed, the presence of amino and sulfonate groups in the film adsorbed on the membrane leads to the complexation of metal ions by these chelating groups. Ion complexation in the membrane along with either ligand diffusion across the membrane or ion hopping between immobile binding sites has already been evidenced by Noble [65]. The group of Bruening also succeeded in retaining high amounts of copper ions using aminated polyelectrolytes [66]. This was confirmed by Bessbousse et al. who used membranes composed of poly(vinyl alcohol) and polyethyleneimine to chelate $\mathrm{Pb}(\mathrm{II}), \mathrm{Cu}$ (II) and Cd(II) ions [67]. Finally, the group of Tieke specifically studied the complexation by assemblies made of $p$-sulfonatocalix[ $n$ ]arenes and poly(vinyl amine) and proved that, if the complexation has to be taken into account, the electrostatic interaction remains predominant in the retention of metal ions even when polymers containing sulfonates or amines which possess numerous binding sites are used [68].

\section{Conclusions}

The present work investigated the performance of a process combining filtration and adsorption and allowing removing polluting metal ions from aqueous solutions. The adsorption capacity of both adsorbents was shown to be high compared to other adsorbents used in the literature. Indeed, $\mathrm{SiO}_{2}$-cyclam adsorbent had an adsorption capacity between 33 and $61 \mathrm{mg} \mathrm{g}^{-1}$ towards $\mathrm{Cu}(\mathrm{II}), \mathrm{Ni}(\mathrm{II})$ and $\mathrm{Zn}(\mathrm{II})$ ions while the adsorption capacity of $\mathrm{SiO}_{2}-\mathrm{CMCS}$ was between 45 and $68 \mathrm{mg} \mathrm{g}^{-1}$ towards the same metal cations. Thus, $\mathrm{SiO}_{2}-\mathrm{CMCS}$ hybrid materials presented a slightly higher adsorption capacity due to the presence of amino and carboxylate functional groups in their structure which are both able to chelate metal ions. Moreover, it was shown that the affinity of both adsorbents for the different ions decreased in the order: $\mathrm{Cu}$ (II) $>\mathrm{Ni}$ (II) $>\mathrm{Zn}$ (II).

The ability to remove metal ions from aqueous solutions using polymer-modified membranes was also studied and led to very satisfactory metal uptake at the lowest concentrations tested (50 and $400 \mathrm{mg} \mathrm{L}^{-1}$ ). On the contrary, at very high metal concentration (800 and $1200 \mathrm{mg} \mathrm{L}^{-1}$ ), filtration was not efficient enough and so it was decided to combine filtration with adsorption to enhance the metal removal.

Thanks to the coupling of the filtration membranes with silica-based adsorbents, very good uptake of the metals was obtained at both low and high metal concentrations, indicating that this strategy constitutes a viable option for metal removal in aqueous solutions which opens the way to its potential use in industrial wastewater treatment.

The removal mechanism was also discussed and the metal uptake was attributed to three main contributions acting simultaneously: the coordination interaction between amino, carboxylate and sulfonate groups of the polymer modifying the membranes and of the molecules modifying the silica particles, electrostatic interactions between the charged polyelectrolyte film and the metal cations, and steric effects due to the functionalization of the pores walls of the membranes.

Author Contributions: S.L. and C.M. conceived and designed the filtration experiments; M.A.M. performed the filtration experiments; M.A. synthesized $\mathrm{SiO}_{2}-\mathrm{CMCS}$ hybrid materials; S.C. and A.M. synthesized $\mathrm{SiO}_{2}-\mathrm{Cyclam}$ hybrid materials; and M.E. and B.L. analyzed the adsorption data. All authors contributed to the revision of the paper.

Conflicts of Interest: The authors declare no conflict of interest.

\section{References}

1. Brandt, M.J.; Johnson, K.M.; Elphinston, A.J.; Ratnayaka, D.D. Twort's Water Supply, 7th ed.; Elsevier: Amsterdam, The Netherlands, 2017; 932p, ISBN 9780081022559.

2. Clemens, S.; Ma, J.F. Toxic heavy metal and metalloid accumulation in crop plants and foods. Annu. Rev. Plant Biol. 2016, 67, 489-512. [CrossRef] [PubMed]

3. Nriagu, J.O. History of global metal pollution. Science 1996, 272, 223-224. [CrossRef] 
4. Wang, Q.; Yang, Z. Industrial water pollution, water environment treatment, and health risks in China. Environ. Pollut. 2016, 218, 359-365. [CrossRef] [PubMed]

5. Jarup, L. Hazards of heavy metal contamination. Br. Med. Bull. 2003, 68, 167-182. [CrossRef] [PubMed]

6. Moiseenko, T.I.; Megorskii, V.V.; Gashkina, N.A.; Kudryavtseva, L.P. Water Pollution Effect on Population Health in an Industrial Northern Region. Water. Res. 2010, 37, 194-203. [CrossRef]

7. Fu, F.; Wang, Q. Removal of heavy metal ions from wastewaters: A review. J. Environ. Manag. 2011, 92, 407-418. [CrossRef] [PubMed]

8. Mohsen-Nia, M.; Montazeri, P.; Modarress, H. Removal of $\mathrm{Cu}^{2+}$ and $\mathrm{Ni}^{2+}$ from wastewater with a chelating agent and reverse osmosis processes. Desalination 2007, 217, 276-281. [CrossRef]

9. Escobar, I.C.; Van der Bruggen, C. Modern Applications in Membrane Science and Technology; ACS Symposium Series; American Chemical Society: Washington, DC, USA, 2011; Volume 1078.

10. Abu Qdais, H.; Moussa, H. Removal of heavy metals from wastewater by membrane processes: A comparative study. Desalination 2004, 164, 105-110. [CrossRef]

11. Gherasim, C.V.; Hanckova, K.; Palarcik, J.; Mikulasek, P. Investigation of cobalt (II) retention from aqueous solutions by a polyamide nanofiltration membrane. J. Membr. Sci. 2015, 490, 46-56. [CrossRef]

12. Basaran, G.; Kavak, D.; Dizge, N.; Asci, Y.; Solener, M.; Ozbey, B. Comparative study of the removal of nickel(II) and chromium(VI) heavy metals from metal plating wastewater by two nanofiltration membranes. Desal. Water Treat. 2016, 57, 21870-21880. [CrossRef]

13. Ng, L.Y.; Mohammad, A.W.; Ng, C.Y. A review on nanofiltration membrane fabrication and modification using polyelectrolytes: Effective ways to develop membrane selective barriers and rejection capability. Adv. Colloid Interface Sci. 2013, 197-198, 85-107. [CrossRef] [PubMed]

14. Wang, J.; Yao, Y.; Yue, Z. Preparation of polyelectrolyte multilayer films consisting of sulfonated poly(ether ketone) alternating with selected anionic layers. J. Membr. Sci. 2009, 337, 200-207. [CrossRef]

15. Park, J.; Park, J.; Kim, S.H.; Cho, J.; Bang, J. Desalination membranes from pH-controlled and thermally-crosslinked layer-by-layer assembled multilayers. J. Mater. Chem. 2010, 20, 2085-2091. [CrossRef]

16. Fadhillah, F.; Zaidi, S.M.J.; Khan, Z.; Khaled, M.M.; Rahman, F.; Hammond, P.T. Development of polyelectrolyte multilayer thin film composite membrane for water desalination application. Desalination 2013, 318, 19-24. [CrossRef]

17. Magnenet, C.; Jurin, F.E.; Lakard, S.; Buron, C.C.; Lakard, B. Polyelectrolyte modification of ultrafiltration membrane for removal of copper ions. Coll. Surf. A 2013, 435, 170-177. [CrossRef]

18. Magnenet, C.; Lakard, S.; Buron, C.C.; Lakard, B. Functionalization of organic membranes by polyelectrolyte multilayer assemblies: Application to the removal of copper ions from aqueous solutions. J. Colloid Interface Sci. 2012, 376, 202-208. [CrossRef]

19. Mokhter, M.A.; Lakard, S.; Magnenet, C.; Euvrard, M.; Lakard, B. Preparation of polyelectrolyte-modified membranes for heavy metal ions removal. Environ. Technol. 2017, 38, 2476-2485. [CrossRef] [PubMed]

20. Qin, Z.P.; Geng, C.L.; Guo, H.X.; Du, Z.; Zhang, G.J.; Ji, S.L. Synthesis of positively charged polyelectrolyte multilayer membranes for removal of divalent metal ions. J. Mater. Res. 2013, 28, 1449-1457. [CrossRef]

21. Kochan, J.; Wintgens, T.; Wong, J.E.; Melin, T. Polyelectrolyte-modified polyethersulfone ultrafiltration membranes for wastewater treatment applications. Desal. Water Treat. 2009, 9, 175-180. [CrossRef]

22. Corapcioglu, M.O.; Huang, C.P. The adsorption of heavy metals onto hydrous activated carbon. Water Res. 1987, 21, 1031-1044. [CrossRef]

23. Kang, K.C.; Kim, S.S.; Choi, J.W.; Kwon, S.H. Sorption of $\mathrm{Cu}^{2+}$ and $\mathrm{Cd}^{2+}$ onto acid- and base- pretreated granular activated carbon and activated carbon fiber samples. J. Ind. Eng. Chem. 2008, 14, 131-135. [CrossRef]

24. Kim, D.S. The removal by crab shell of mixed heavy metal ions in aqueous solution. Bioresour. Technol. 2003, 87, 355-357. [CrossRef]

25. Vold, I.M.N.; Varum, K.M.; Guibal, E.; Smidsrod, O. Binding of ions to chitosan-Selectivity studies. Carbohydr. Polym. 2003, 54, 471-477. [CrossRef]

26. Guibal, E.; Vincent, T.; Navarro, R. Metal ion biosorption on chitosan for the synthesis of advanced materials. J. Mater. Sci. 2014, 49, 5505-5518. [CrossRef]

27. Benhamou, A.; Baudu, M.; Derriche, Z.; Basly, J.P. Aqueous heavy metals removal on amine-functionalized Si-MCM-41 and Si-MCM-48. J. Hazard. Mater. 2009, 171, 1001-1008. [CrossRef] [PubMed]

28. Aguado, J.; Arsuaga, J.M.; Arencibia, A.; Lindo, M.; Gascon, V. Aqueous heavy metals removal by adsorption on amine-functionalized mesoporous silica. J. Hazard. Mater. 2009, 163, 213-221. [CrossRef] [PubMed] 
29. Koong, L.F.; Lam, K.F.; Barford, J.; McKay, G. A comparative study on selective adsorption of metal ions using aminated adsorbents. J. Colloid Interface Sci. 2013, 395, 230-240. [CrossRef] [PubMed]

30. Alauzun, J.; Besson, E.; Mehdi, A.; Corriu, R.J.P. Reversible covalent chemistry of $\mathrm{CO}_{2}$ : An opportunity for nano-structured hybrid organic-inorganic materials. Chem. Mater. 2008, 20, 503-513. [CrossRef]

31. Munoz, S.V.; Martinez, M.S.; Torres, M.G.; Alcala, S.P.; Quintanilla, F.; Rodriguez-Canto, A.; Rodriguez, J.R. Adsorption and Removal of Cadmium Ions from Simulated Wastewater Using Commercial Hydrophilic and Hydrophobic Silica Nanoparticles: A Comparison with Sol-gel Particles. Water Air Soil Pollut. 2014, 225, 2165-2176. [CrossRef]

32. Singhon, R.; Husson, J.; Knorr, M.; Lakard, B.; Euvrard, M. Adsorption of Ni(II) ions on colloidal hybrid organic-inorganic silica composites. Coll. Surf. B 2012, 93, 1-7. [CrossRef] [PubMed]

33. Singhon, R.; Husson, J.; Knorr, M.; Euvrard, M. Preparation of Silica-Supported Biosorbents for Copper(II) Removal. J. Disp. Sci. Technol. 2011, 32, 1735-1741. [CrossRef]

34. Kavakli, C.; Ali Tuncel, S.; Salih, B. Selectivity of cyclam modified poly( $p$-chloromethyl styrene-ethyleneglycol dimethacrylate) microbeads for $\mathrm{Cu}(\mathrm{II}), \mathrm{Ni}(\mathrm{II}), \mathrm{Co}$.(II) and Zn(II). Sep. Purif. Technol. 2005, 45, 32-40. [CrossRef]

35. Dubois, G.; Reyé, C.; Corriu, J.P.; Brandes, S.; Denat, F.; Guilard, R. Coordination chemistry in the solid: Study of the incorporation of $\mathrm{Cu}(\mathrm{II})$ into cyclam-containing hybrid materials. Angew. Chem. 2001, 40, 1087-1090. [CrossRef]

36. Katsou, E.; Malamis, S.; Kosanovic, T.; Souma, K.; Haralambous, K.J. Application of adsorption and ultrafiltration processes for the pre-treatment of several industrial wastewater streams. Water Air Soil Pollut. 2012, 223, 5519-5534. [CrossRef]

37. Malamis, S.; Katsou, E.; Haralambous, K.J. Study of $\mathrm{Ni}(\mathrm{II}), \mathrm{Cu}(\mathrm{II}), \mathrm{Pb}(\mathrm{II})$ and $\mathrm{Zn}(\mathrm{II})$ removal using sludges and minerals followed by UF/MF. Water Air Soil Pollut. 2011, 218, 81-92. [CrossRef]

38. Malamis, S.; Katsou, E.; Kosanovic, T.; Haralambous, K.J. Combined adsorption and ultrafiltration processes employed for the removal of pollutants from metal plating wastewater. Sep. Sci. Technol. 2012, 47, 983-996. [CrossRef]

39. Malamis, S.; Katsou, E.; Haralambous, K.J. Evaluation of the efficiency of a combined adsorptionultrafiltration system for the removal of heavy metals, color, and organic matter from textile wastewater. Sep. Sci. Technol. 2011, 46, 920-932. [CrossRef]

40. Decher, G. Fuzzy nanoassemblies: Toward layered polymeric multicomposites. Nature 1997, 277, $1232-1237$. [CrossRef]

41. Dirieh Egueh, A.N.; Lakard, B.; Fievet, P.; Lakard, S.; Buron, C. Charge properties of membranes modified by multilayer polyelectrolyte adsorption. J. Colloid Interface Sci. 2010, 344, 221-227. [CrossRef] [PubMed]

42. Liang, P.; Zhao, Y.; Shen, Q.; Wang, D.; Xu, D.; et al. The effect of carboxymethyl chitosan on the precipitation of calcium carbonate. J. Cryst. Growth 2004, 261, 571-576. [CrossRef]

43. Aden, M.; Ubol, R.N.; Knorr, M.; Husson, J.; Euvrard, M. Efficent removal of nickel(II) salts from aqueous solution using carboxymethylchitosan-coated silica particles as adsorbent. Carbohydr. Polym. 2017, 173, 372-382. [CrossRef] [PubMed]

44. Makowska-Janusik, M.; Kassiba, A.; Errien, N.; Mehdi, A.J. Mesoporous Silica Functionalized by Cyclam-Metal Groups: Spectroscopic Studies and Numerical Modeling. J. Inorg. Organomet. Polym. 2010, 20, 761-773. [CrossRef]

45. Foo, K.Y.; Hameed, B.H. Insights into the modeling of adsorption isotherm systems. Chem. Eng. J. 2010, 156, 2-10. [CrossRef]

46. Alqadami, A.A.; Naushad, M.; Abdalla, M.A.; Ahamad, T.; AlOthman, Z.A.; Alshehri, S.M.; Ghfar, A.A. Efficient removal of toxic metal ions from wastewater recyclable nanocomposite: A study of adsorption parameters and interaction mechanism. J. Clean. Prod. 2017, 156, 426-436. [CrossRef]

47. Ringot, D.; Lerzy, B.; Chaplain, K.; Bonhoure, J.P.; Auclair, E.; Larondelle, Y. In vitro biosorption of ochratoxin A on the yeast industry by-products: Comparison of isotherm models. Bioresour. Technol. 2007, 98, 1812-1821. [CrossRef] [PubMed]

48. Van Erp, T.S.; Martens, J.A. A standardization for BET fitting of adsorption isotherms. Microporous Mesoporous Mater. 2011, 145, 188-193. [CrossRef]

49. Shim, J.W.; Park, S.J.; Ryu, S.K. Effect of modification with $\mathrm{HNO}_{3}$ and $\mathrm{NaOH}$ on metal adsorption by pitch-based activated carbon fibers. Carbon 2001, 39, 1635-1642. [CrossRef] 
50. Monser, L.; Adhoum, N. Modified activated carbon for the removal of copper, zinc, chromium and cyanide from wastewater. Sep. Purif. Technol. 2002, 26, 137-146. [CrossRef]

51. Babel, S.; Kurniawan, T.A. Low-cost adsorbent for heavy metals uptake from contaminated water: A review. J. Hazard. Mater. 2003, 97, 219-243. [CrossRef]

52. O'Connell, D.W.; Birkinshaw, C.; O'Dwyer, T.F. Heavy metal adsorbents prepared from the modification of cellulose: A review. Bioresour. Technol. 2008, 99, 6709-6724. [CrossRef] [PubMed]

53. Algarra, M.; Jimenez, M.V.; Rodriguez-Castellon, E.; Jimenez-Lopez, A.; Jimenez-Jimenez, J. Heavy metals removal from electroplating wastewater by aminopropyl-Si MCM-41. Chemosphere 2005, 59, 779-786. [CrossRef] [PubMed]

54. Lee, B.; Kim, Y.; Lee, H.; Yi, J. Synthesis of functionalized porous silica via templating method as heavy metal ion adsorbents: The introduction of surface hydrophilicity onto the surface of adsorbents. Microporous Mesoporous Mater. 2001, 50, 77-90. [CrossRef]

55. Jiang, Y.; Gao, Q.; Yu, H.; Chen, J.R.; Deng, F. Intensively competitive adsorption for heavy metal ions by PAMAM-SBA-15 and EDTA-PAMAM-SBA-15 inorganic-organic hybrid materials. Microporous Mesoporous Mater. 2007, 103, 316-324. [CrossRef]

56. Ngah, W.S.W.; Isa, I.M. Comparison study of copper ion adsorption on chitosan, Dowex A-1, and Zerolit 225. J. Appl. Polym. Sci. 1998, 67, 1067-1070. [CrossRef]

57. McKay, G.; Blair, H.S.; Findon, A. Equilibrium studies for the sorption of metal-ions onto chitosan. Ind. J. Chem. 1989, 28, 356-360.

58. Escoda, A.; Euvrard, M.; Lakard, S.; Husson, J.; Mohamed, A.S.; Knorr, M. Ultrafiltration-assisted retention of $\mathrm{Cu}$ (II) ions by adsorption on chitosan-functionalized colloidal silica particles. Sep. Purif. Technol. 2013, 118, 25-32. [CrossRef]

59. Dambies, L.; Guimon, C.; Yiacoumi, E.; Guibal, E. Characterization of metal ion interactions with chitosan by X-ray photoelectron spectroscopy. J. Collid Interface Sci. 2001, 177, 203-214. [CrossRef]

60. Juang, R.S.; Shao, H.J. Effect of $\mathrm{pH}$ on competitive adsorption of $\mathrm{Cu}(\mathrm{II}), \mathrm{Ni}(\mathrm{II})$, and $\mathrm{Zn}$ (II) from water onto chitosan beads. Adsorption 2002, 8, 71-78. [CrossRef]

61. Mureseanu, M.; Reiss, A.; Stefanescu, I.; David, E.; Parvulescu, V.; Renard, G.; Hulea, V. Modified SBA-15 mesoporous silica for heavy metal ions remediation. Chemosphere 2008, 73, 1499-1504. [CrossRef] [PubMed]

62. Shriver, D.F.; Atkins, P.W. Inorganic Chemistry, 3rd ed.; Oxford University Press: Oxford, UK, 1999; 763p, ISBN 0198503318.

63. Monteiro, O.A.C., Jr.; Airoldi, C. Some thermodynamic data on copper-chitin and copper-chitosan biopolymer interactions. J. Collid Interface Sci. 1999, 212, 212-219. [CrossRef] [PubMed]

64. Martell, A.E.; Smith, R.M. Critical Stability Constants, 1st ed.; Plenum Press: New York, NY, USA, 1974; Volume 4, 276p, ISBN 0306352141.

65. Noble, R.D. Generalized microscopic mechanism of facilitated transport in fixed site carrier membranes. J. Membr. Sci. 1992, 75, 121-129. [CrossRef]

66. Sheng, C.; Wijeratne, S.; Cheng, S.; Baker, G.L.; Bruening, M.L. Facilitated ion transport through polyelectrolyte multilayer films containing metal-binding ligands. J. Membr. Sci. 2014, 459, 169-176. [CrossRef]

67. Bessbousse, H.; Verchère, J.F.; Lebrun, L. Characterisation of metal-complexing membranes prepared by the semi-interpenetrating polymer networks technique. Application to the removal of heavy metal ions from aqueous solutions. Chem. Eng. J. 2012, 187, 16-28. [CrossRef]

68. Toutianoush, A.; Schnepf, J.; El Hashani, A.; Tieke, B. Selective ion transport and complexation in layer-by-layer assemblies made of p-sulfanoto calix[n]arenes and cationic polyelectrolytes. Adv. Func. Mater. 2005, 15, 700-708. [CrossRef]

(C) 2018 by the authors. Licensee MDPI, Basel, Switzerland. This article is an open access article distributed under the terms and conditions of the Creative Commons Attribution (CC BY) license (http:/ / creativecommons.org/licenses/by/4.0/). 